\title{
Air contamination with SARS-CoV-2 in the operating room
}

\author{
Kazuyoshi Hirota' ${ }^{10}$
}

Received: 23 May 2020 / Accepted: 6 June 2020 / Published online: 19 June 2020

(c) Japanese Society of Anesthesiologists 2020

\begin{abstract}
Angiotensin converting enzyme 2 (ACE2) is a target cell receptor for internalization and proliferation of the severe acute respiratory syndrome coronavirus 2 (SARS-CoV-2). When ACE2-highly expressed tissues are manipulated, SARS-CoV-2 containing aerosols may be generated. Normal breathing and speaking are capable of producing aerosols so mask ventilation, suction of airway tract and bucking during tracheal intubation and extubation are clinical procedures capable of significant aerosol production. Whilst no data have been reported on the distribution of SARS-CoV-2 in the operating room (OR), contamination in the OR can be estimated from the intensive care unit (ICU) data. ICU data showed that SARS-CoV-2 was detected on all types of surface and in air within about $4 \mathrm{~m}$ from coronavirus disease 2019 (COVID-19) patients. High concentrations of SARS-CoV-2 was detected in the personal protective equipment (PPE) removal room and medical staff office. Submicron virus-laden aerosols could result from resuspension of particles containing SARS-CoV-2 sticking the PPE surface; removal could produce the initial velocity. Supermicron virus-laden aerosol could come from floor deposited SARS-CoV-2, which were carried across different areas by medical staff (e.g., shoe). Knowledge of aerosol generation and distribution in the OR will aid the design of strategies to reduce transmission risk.
\end{abstract}

Keywords COVID-19 $\cdot$ Aerosol $\cdot$ Operating room

\section{Introduction}

The first novel severe acute respiratory syndrome coronavirus 2 (SARS-CoV-2) disease (COVID-19) patient was identified on December 82019 in Wuhan, China [1]. The COVID-19 has spread rapidly and is now a global pandemic. Japan is also subject to lockdown in all prefectures to prevent spread. By May 5th more than 15,000 COVID-19 patients were reported in Japan with a mortality rate of around 3.5\% [2]. Anesthesiologists are one of healthcare worker groups with the highest risk of contracting COVID-19 as they are likely to be exposed to SARS-CoV-2 via patient generated aerosols from cough, bucking during mask ventilation, tracheal intubation and extubation, airway suctioning and bronchoscopy. Following confirmation of community acquired infection with COVID-19 in the middle of February 2020 in Japan, the Japanese Society of Anesthesiologists (JSA)

Kazuyoshi Hirota

hirotak@hirosaki-u.ac.jp

1 Department of Anesthesiology, Hirosaki University Graduate School of Medicine, Hirosaki 036-8562, Japan published practical guidance (in Japanese) for anesthesia management and tracheal intubation in COVID-19 patients (JSA homepage; March 3, 2020 https://anesth.or.jp/img/ upload/ckeditor/files/2004_07_01.pdf). Knowledge of aerosol generation and distribution in the operating room (OR) will aid the design of strategies to reduce transmission risk.

\section{SARS-CoV-2 proliferation sites}

Angiotensin converting enzyme 2 (ACE2) has been confirmed to be a target cell receptor for internalization of SARS-CoV-2 and is dependent on transmembrane serine protease 2 (TMPRSS2) [3]. Infectivity of SARS-CoV-2 is enhanced and inhibited by the presence of TMPRSS 2 and a serine protease inhibitor, respectively [3]. The SARS-CoV-2 cell receptor gene ACE2 is widely expressed in human cells and tissues such as lymphocytes/dendritic cells, type 2 pneumocytes, bronchial epithelium, nasal cavity olfactory epithelium, esophagus, gastrointestinal smooth muscle, myocardium, vascular smooth muscle, neurons, liver and kidney [4-7]. Although the respiratory tract is recognized as a site for spread of SARS-CoV-2 infection, higher expression of 
Table 1 Expression of SARS-CoV-2 cell receptor gene ACE2 in various tissues [2]

\author{
High expression tissues \\ Small intestine, testis, kidneys, heart, thyroid, adipose tissue \\ Middle expression tissues \\ Lungs, colon, liver, bladder, adrenal gland \\ Low expression tissues \\ Blood, spleen, bone marrow, brain, blood vessels, muscles
}

ACE2 is detected in the small intestine, testis, kidneys, heart, thyroid, and adipose tissue than the lungs (Table 1). Thus, SARS-CoV-2 can infect and proliferate in these tissues. In addition, SARS-CoV-2 RNA has been detected in saliva and ACE2 is expressed in epithelial cells in the minor salivary gland ducts [8] although the expression of TMPRSS2 in salivary glands is unknown. ACE2 was not detected in the vocal folds, epiglottis and trachea [9].

\section{Perioperative risk factors for aerosol generation}

In the previous section, proliferation sites of SARS-CoV-2 are listed. When these tissues are manipulated aerosols containing SARS-CoV-2 may be generated. Normal breathing and speaking are capable of producing aerosols so mask ventilation, suction of the airway tract and bucking during tracheal intubation and extubation are clinical procedures capable of significant aerosol production [10, 11]. Bronchoscopy is also well-known as an aerosol generating procedure [12]. Otolaryngologic surgical procedures are high risk as it is performed close to the upper respiratory tract with mucus, secretions and droplets present. Although use of cold instrumentation (e.g., surgical forceps and knifes) and microdebrider may not cause detectable aerosol production, use of a high-speed drill generates a significant aerosol [13]. Laparoscopic and robot assisted surgery may be safer for medical staff via a reduction of contact with contaminated body fluid, tissues and evaporative gases from the surgical area. As ultrasonic systems may not provide enough heat to deactivate SARS-CoV-2, these procedures produce intra-abdominal aerosols containing SARS-CoV-2 [14, 15]. Therefore, aerosol leakage may occur at extraction of the surgical ports and exsufflation of pneumoperitoneum.

\section{Distribution of air contamination by aerosol}

Heating, ventilation and air conditioning (HVAC) systems are effective tools in the control of airborne infection. However, when this system is incorrectly used, it may contribute to the spread of airborne infection [16]. A knowledge of the HVAC system and aerosol aerodynamics in important in the prevention of airborne infection from SARS-CoV-2.

\section{Aerodynamics of coughing, sneezing and breathing}

Tang and colleagues $[11,17]$ used a real-time shadowgraph imaging technique to examine airflow dynamics during coughing, sneezing and breathing in healthy volunteers (20 subjects for coughing and breathing, another 6 subjects for sneezing). These authors reported the maximum total propagation distance, derived velocities and the 2-dimensional (2D) area as shown in Table 2 . They found that the maximum cough and sneeze velocities were only 3-4 times faster than breathing. Propagation distance and 2D projected area were similar between cough, sneeze and breathing. Dudalski and colleagues [18] found that neither velocity nor turbulence characteristics were different between coughs from influenza-infected and healthy subjects.

\section{Distribution of SARS-CoV-2}

No data have been reported on the distribution of SARSCoV-2 in the OR when COVID-19 patients undergo surgery. Contamination in the OR can be estimated from other data. Guo and colleagues [19] determined distribution of SARS-CoV-2 in the hospital in Wuhan, China. They collected surface samples from the floors, computer mice, trash cans, sickbed handrails, patient masks, personal protective equipment (PPE) and air outlets using sterile premoistened swabs. They also collected air samples from the intensive care unit (ICU: 15 severe COVID-19 patients) and general COVID-19 ward (GW: 24 milder disease patients) using a SASS 2300 Wetted Wall Cyclone Sampler (Research International Inc, USA) at $300 \mathrm{~L} / \mathrm{min}$ for of $30 \mathrm{~min}$. They tested air and surface samples to detect SARS-CoV-2 by quantitative real-time polymerase chain reaction assays. SARSCoV-2 was detected from all types of surface and was also detected in air within about $4 \mathrm{~m}$ from COVID-19 patients. The return of positive swabs was much higher in the ICU than GW. Floor swab samples in the ICU showed relatively high positive rates: $7 / 10(70 \%)$. This could be due to virus droplets from the aerosol falling due to gravity and air flow to the floor. In addition, as $100 \%$ positive rate was found on the floor in the pharmacy where there were no COVID19 patients, contaminated shoes are also likely to spread

Table 2 Airflow analysis data [16]

\begin{tabular}{llll}
\hline & Velocity $(\mathrm{m} / \mathrm{s})$ & $\begin{array}{l}\text { 2D Projected } \\
\text { area }\left(\mathrm{m}^{2}\right)\end{array}$ & $\begin{array}{l}\text { Propagation } \\
\text { distance }(\mathrm{m})\end{array}$ \\
\hline Sneeze & 4.5 & 0.20 & 0.6 \\
Cough & 5.0 & 0.20 & 0.7 \\
$\begin{array}{l}\text { Breathing } \\
\text { Nasal }\end{array}$ & 1.4 & & \\
Oral & 1.3 & 0.11 & 0.6 \\
\hline
\end{tabular}


SARS-CoV-2. In the OR, coughing after tracheal intubation/ extubation is often observed. As coughing generally produces not only aerosol but also droplet that may disperse within a maximum $2 \mathrm{~m}$ radius [20]. Therefore, shoe covers should be used and changed to prevent the spread of the contamination whenever leaving the OR. As the highest positive rates were shown for computer mice in the ICU: $6 / 8$ (75\%), these should always be cleaned before and after OR use of electronic anesthesia record system. Ventilation was performed more often in the ICU (12 air supplies and 16 air discharges/h) than the GW (8 air supplies and 12 air discharges/h). However, the positive rate for air samples was higher in the ICU: $14 / 40$ (35\%) than that in GW: $2 / 16$ (12.5\%). High SARS-CoV-2 air contamination may occur by aerosol generation when mask ventilation, tracheal intubation and extubation and also surgical procedures in surgical fields including SARS-CoV-2 proliferation sites are done. Liu and colleagues [21] performed aerodynamic analysis of SARV-CoV-2 in 2 hospitals in Wuhan, China. They measured airborne SARS-CoV-2 RNA in different areas. SARSCoV-2 RNA in aerosols was detected at very low level in isolation wards and ventilated patient rooms. However, it was detected at high levels in the patients' toilet areas as both the kidney and intestine are virus proliferation sites. They also found that high concentrations of SARS-CoV-2 RNA was detected in PPE removal rooms and medical staff office. However, aerosol size distributions were different between PPE removal rooms and medical staff office. The submicron region was dominantly observed in PPE removal rooms while the supermicron region was observed in the medical staff office. The submicron virus-laden aerosol could be due to the resuspension of particles containing SARS-CoV-2 sticking to the PPE surface as PPE removal could produce the initial velocity while supermicron virus-laden aerosol could come from floor deposited SARS-CoV-2, which were carried across different areas by medical staff (e.g., shoe). As viral aerosols may be easily generated by PPE removal this is difficult to avoid. Ma and colleagues [22] reported that N95 masks blocked nearly all avian influenza virus in aerosol which was used as pseudo SARS-CoV-2 while standard medical masks blocked about $97 \%$ of the virus. In addition, face mask fit is crucial to prevent air leakage and inflow of aerosol via a gap between mask edge and the skin. N95 mask is much better than standard medical mask [23, 24]. As standard medical masks cannot not fully protect aerosol, N95 mask must be preferable. Another problem is that most ORs are pressurized. Thus, if aerosol generation occurs in some OR, other ORs on the same floor are also likely to be contaminated. Depressurized and/or isolated ORs are preferable.

In conclusion, to prevent or reduce aerosol generation and distribution, anesthesiologists should know how aerosols are generated and distributed in the OR. Distribution can be reduced by slow and careful removal of PPE and change of shoe covers whenever leaving the depressurized and/or isolated OR. In addition, an N95 mask correctly applied to provide a close face seal can prevent inhalation of SARS$\mathrm{CoV}-2$ aerosol in the OR.

Acknowledgment I thank Professor David G. Lambert (University Department of Cardiovascular Sciences, Anaesthesia, Critical Care and Pain Management, Leicester Royal infirmary, Leicester, UK) for his valuable comments.

\section{References}

1. Lou J, Tian S-J, Niu S-M, Kang X-Q, Lian H-X, Zhang L-X, Zhang J-J. Coronavirus disease 2019: a bibliometric analysis and review. Eur Rev Med Pharmacol Sci. 2020;24:3411-21.

2. Ogiwara K. Coronavirus disease (COVID-19) situation report in Japan (2020 May 5 Data) https://toyokeizai.net/sp/visual/tko/covid 19/en.html.

3. Hoffmann M, Kleine-Weber H, Schroeder S, Krüger N, Herrler T, Erichsen S, Schiergens TS, Herrler G, Wu NH, Nitsche A, Müller MA, Drosten C, Pöhlmann S. SARS-CoV-2 cell entry depends on ACE2 and TMPRSS2 and is blocked by a clinically proven protease inhibitor. Cell. 2020;181:271-80.

4. Li MY, Li L, Zhang Y, Wang XS. Expression of the SARS-CoV-2 cell receptor gene ACE2 in a wide variety of human tissues. Infect Dis Poverty. 2020;9:45.

5. Liu PP, Blet A, Smyth D, Li H. The science underlying COVID19: implications for the cardiovascular system. Circulation. 2020. https://doi.org/10.1161/CIRCULATIONAHA.120.047549.

6. Butowt R, Bilinska K. SARS-CoV-2: olfaction, brain Infection, and the urgent need for clinical samples allowing earlier virus detection. ACS Chem Neurosci. 2020. https://doi.org/10.1021/ acschemneuro.0c00172.

7. D'Amico F, Baumgart DC, Danese S, Peyrin-Biroulet L. Diarrhea during COVID-19 infection: pathogenesis, epidemiology, prevention and management. Clin Gastroenterol Hepatol. 2020. https:// doi.org/10.1016/j.cgh.2020.04.001.

8. Xu R, Cui B, Duan X, Zhang P, Zhou X, Yuan Q. Saliva: potential diagnostic value and transmission of 2019-nCoV. Int J Oral Sci. 2020;12:11.

9. Bertram S, Heurich A, Lavender H, Gierer S, Danisch S, Perin P, Lucas JM, Nelson PS, Pöhlmann S, Soilleux EJ. Influenza and SARS-coronavirus activating proteases TMPRSS2 and HAT are expressed at multiple sites in human respiratory and gastrointestinal tracts. PLoS ONE. 2012;7:e35876.

10. Chao CYH, Wan MP, Morawska L, Johnson GR, Ristovski ZD, Hargreaves M, Mengersen K, Corbett S, Li Y, Xie X, Katoshevski D. Characterization of expiration air jets and droplet size distributions immediately at the mouth opening. J Aerosol Sci. 2009;40:122-33.

11. Tang JW, Nicolle AD, Klettner CA, Pantelic J, Wang L, Suhaimi AB, Tan AY, Ong GW, Su R, Sekhar C, Cheong DD, Tham KW. Airflow dynamics of human jets: sneezing and breathing - potential sources of infectious aerosols. PLoS ONE. 2013;8:e59970.

12. Zietsman M, Phan LT, Jones RM. Potential for occupational exposures to pathogens during bronchoscopy procedures. J Occup Environ Hyg. 2019;16:707-16.

13. Workman AD, Welling DB, Carter BS, Curry WT, Holbrook EH, Gray ST, Scangas GA, Bleier BS. Endonasal instrumentation and aerosolization risk in the era of COVID-19: simulation, literature 
review, and proposed mitigation strategies. Int Forum Allergy Rhinol. 2020. https://doi.org/10.1002/alr.22577.

14. Veziant J, Bourdel N, Slim K. Risks of viral contamination in healthcare professionals during laparoscopy in the Covid-19 pandemic. J Visc Surg. 2020. https://doi.org/10.1016/j.jvisc surg.2020.04.010.

15. Kimmig R, Verheijen RHM, Rudnicki M, for SERGS Council. Robot assisted surgery during the COVID-19 pandemic, especially for gynecological cancer: a statement of the Society of European Robotic Gynaecological Surgery (SERGS). J Gynecol Oncol. 2020;31:e59.

16. Correia G, Rodrigues L, Gameiro Da Silva M, Gonçalves T. Airborne route and bad use of ventilation systems as non-negligible factors in SARS-CoV-2 transmission. Med Hypotheses. 2020;141:109781.

17. Tang JW, Nicolle A, Pantelic J, Koh GC, Wang LD, Amin M, Klettner CA, Cheong DK, Sekhar C, Tham KW. Airflow dynamics of coughing in healthy human volunteers by shadowgraph imaging: an aid to aerosol infection control. PLoS ONE. 2012;7:e34818.

18. Dudalski N, Mohamed A, Mubareka S, Bi R, Zhang C, Savory E. Experimental investigation of far-field human cough airflows from healthy and influenza-infected subjects. Indoor Air. 2020. https:// doi.org/10.1111/ina.12680.

19. Guo ZD, Wang ZY, Zhang SF, Li X, Li L, Li C, Cui Y, Fu RB, Dong YZ, Chi XY, Zhang MY, Liu K, Cao C, Liu B, Zhang K, Gao YW, Lu B, Chen W. Aerosol and surface distribution of severe acute respiratory syndrome coronavirus 2 in hospital wards, Wuhan, China, 2020. Emerg Infect Dis. 2020. https://doi. org/10.3201/eid2607.200885.

20. Odor PM, Neun M, Bampoe S, Clark S, Heaton D, Hoogenboom EM, Patel A, Brown M, Kamming D. Anaesthesia and COVID-19: infection control. Br J Anaesth. 2020. https://doi. org/10.1016/j.bja.2020.03.025.

21. Liu Y, Ning Z, Chen Y, Guo M, Liu Y, Gali NK, Sun L, Duan Y, Cai J, Westerdahl D, Liu X, Xu K, Ho KF, Kan H, Fu Q, Lan K. Aerodynamic analysis of SARS-CoV-2 in two Wuhan hospitals. Nature. 2020. https://doi.org/10.1038/s41586-020-2271-3.

22. Ma Q-X, Shan H, Zhang H-L, Li G-M, Yang R-M, Chen J-M. Potential utilities of mask-wearing and instant hand hygiene for fighting SARS-CoV-2. J Med Virol. 2020. https://doi.org/10.1002/ jmv.25805.

23. Hui DS. Severe acute respiratory syndrome (SARS): lessons learnt in Hong Kong. J Thorac Dis. 2013;5(Suppl 2):S122-6.

24. Wen Z, Yu L, Yang W, Hu L, Li N, Wang J, Li J, Lu J, Dong X, Yin Z, Zhang K. Assessment the protection performance of different level personal respiratory protection masks against viral aerosol. Aerobiologia (Bologna). 2013;29:365-72.

Publisher's Note Springer Nature remains neutral with regard to jurisdictional claims in published maps and institutional affiliations. 